\title{
Geographic variation in thermal plasticity of life history and wing pattern in Bicyclus anynana
}

\author{
M. A. de Jong*, F. M. N. H. Kesbeke, P. M. Brakefield, B. J. Zwaan \\ Evolutionary Biology Group, Institute of Biology, Leiden University, Sylviusweg 72, 2333 BE Leiden, the Netherlands
}

\begin{abstract}
Temperature is one of the main environmental cues regulating seasonal plasticity in insects. Global climate change may lead to a change in the predictive value of temperature for seasonal conditions, potentially resulting in a mismatch of phenotypic form and environment. The afrotropical butterfly Bicyclus anynana shows striking seasonal plasticity for wing patterns and life history traits. This polyphenism is an adaptation to contrasting patterns of rainfall over wet and dry seasons, and is mainly determined by temperature. To investigate the extent of local adaptation of the developmental plasticity response to regional climate, we compared the thermal reaction norms for several life history traits and wing pattern of 2 distant populations from regions with different temperature-rainfall associations. We found little to no population differentiation for the life history traits, while wing pattern showed substantially more geographic variation. Broad-sense heritabilities and cross-environment correlations for wing pattern and 2 life history traits indicated a potential for adaptation of the plasticity response of these traits. Our results indicate that thermal plasticity of wing pattern can be population-specific; thus climate change may lead to a mismatch of wing pattern to seasonal environment. Traits that can be further modified by acclimation during the butterfly's adult life span (starvation resistance, resting metabolic rate and egg size) showed no geographic differentiation for their developmental plasticity. This indicates that for these traits, adult acclimation plays an important role in coping with local climate.
\end{abstract}

KEY WORDS: Temperature - Developmental plasticity - Seasonal polyphenism · Geographic variation $\cdot$ Life history $\cdot$ Wing pattern $\cdot$ Bicyclus aynana $\cdot$ Acclimation

\section{INTRODUCTION}

For many insects, developmental plasticity is a crucial mechanism to cope with seasonally varying conditions (Shapiro 1976, Gotthard \& Nylin 1995). The ability to change the phenotype in response to environmental cues can be adaptive if the phenotypic variation increases fitness in the environments encountered (Stearns 1976). Adaptive seasonal plasticity has been observed for every stage of the insect life cycle, and includes the timing of key life history events such as diapause (Tauber et al. 1986), plasticity of egg size (e.g. Fischer et al. 2003, Fischer \& Karl 2010, this Special) and thermoregulation by wing melanisation (Shapiro 1976, Kingsolver 1996). An extreme form of developmental plasticity is polyphenism, which involves the development of discrete phenotypes rather than a continuous range of phenotypes in response to the environment (Shapiro 1976). Seasonally induced polyphenism allows insects with multiple generations per year to express the optimal phenotype in each season. Well-known examples are polymorphisms in dispersal (e.g. in aphids, Dixon \& Kindlmann 1999) and seasonally varying wing morphs in Lepidoptera (Brakefield \& Frankino 2009).

Current climate change is having far-reaching effects on biodiversity and species' distributions. In addition to well-documented shifts in species ranges, research is increasingly focusing on the roles of phenotypic plasticity and genetic adaptation in the responses of species to climate change (Chown et al. 2010, Van Dorslaer et al. 2010, Rezende et al. 2010, all this Special). Temperature is one of the main environmental cues involved in inducing seasonal plasticity in organ- 
isms. For seasonal polyphenisms, the inducing environment is often not the same as the selective environment (Nijhout 2003). The organism uses the cue (e.g. temperature) as a reliable predictor of other seasonal conditions (e.g. nutrient stress). However, global warming will have a major impact on average longterm temperature patterns, thereby potentially changing the predictive value of temperature for seasonal conditions. A profound and well-reported result of this is the change in timing of phenology observed for a diversity of species (Root et al. 2003, Parmesan 2006). For polyphenic species, a possible shift in development of phenotypic form relative to the seasonal transitions, resulting in a mismatch between phenotype and environment, could be a very relevant problem. Studying the extent and specificity of the plastic responses to temperature in polyphenic species can help us predict their ability to adapt to climate change.

In the afrotropical butterfly genus Bicyclus and especially in the species B. anynana (Nymphalidae), seasonal polyphenism has been well studied (Brakefield \& Larsen 1984, Brakefield \& Reitsma 1991, Brakefield et al. 2007). This species shows extensive developmental plasticity for wing pattern and life history traits as an adaptation to the strongly contrasting wet and dry seasons of its East African savannah habitat. In the warmer rainy season, food is abundant and conditions are highly favourable for both rapid larval growth and adult reproduction. In contrast, food is scarce or absent in the cooler dry season, and a survival-based strategy is better suited to this part of the year. The seasonal forms of $B$. anynana show striking differences in wing pattern: wet season butterflies typically have conspicuous eyespots and a white band on their ventral wing surfaces, while the cryptic dry season form shows almost no eyespots and is more or less uniformly brown. In addition to wing pattern, $B$. anynana shows developmental plasticity for development time, adult size, adult fat content, starvation resistance, life span, metabolic rate and egg size (Fischer et al. 2003, Brakefield et al. 2007, Pijpe et al. 2007).

Temperature is the single most important climatic variable determining seasonal phenotype in Bicyclus anynana from Malawi, where temperature is highly correlated with rainfall and, thus, provides a reliable indicator for the adaptive seasonal forms (Kooi \& Brakefield 1999). However, patterns of temperature-rainfall correlation vary strongly throughout the geographical distribution of $B$. anynana, and different regions are expected to have posed different selection pressures on the species' plastic responses to temperature (Roskam $\&$ Brakefield 1999). Studying genetic geographic differentiation between populations in relation to associated environmental differences is a common approach to assess the adaptive value of species responses to local conditions (Endler 1986). In the light of climate change, investigating local adaptation can also be used to predict potential adaptation to future conditions, i.e. temperature rises and changes in patterns of seasonality (e.g. Trotta et al. 2010, this Special).

In the present study, we compared 2 populations of Bicyclus anynana from different latitudes in their developmental plasticity response to temperature for wing pattern and several life history (related) traits. One population is from Malawi and lies in the tropics; the other population is located $1400 \mathrm{~km}$ to the south in subtropical South Africa. This large latitudinal distance results in substantial differences in local climate, and monthly average, minimum and maximum temperatures differ by as much as $5^{\circ} \mathrm{C}$. However, for both localities, temperature and rainfall correlations are high. Thus temperature is a good indicator for rainfall in both regions, but specific temperatures correspond to different rainfall patterns between these populations; a temperature experienced in Malawi may be associated with the rainy season, while the same temperature is correlated with the dry season in South Africa. By comparing populations from regions that pose different selection pressures on the species' plastic responses to temperature, we aim to answer the following questions: (1) Is there evidence for geographic variation in the developmental plasticity response to temperature, or does the same plastic response cover a broader range of climates? (2) If the populations indeed show genetic adaptation of their plasticity response to local climate, is the extent of differentiation in the response to developmental temperature consistent for different traits?

To address these questions, we compared the populations in a common garden experiment and measured their reaction norms in response to 3 rearing temperatures for the following traits: developmental time, pupal mass (as a proxy for adult mass), adult fat content, starvation resistance, resting metabolic rate and wing pattern elements. In addition, to further investigate the adaptive potential of developmental plasticity to changing climates, we estimated broad-sense heritabilities and cross-environment correlations for developmental time, pupal mass, fat content and wing pattern in a split full-sibling family design for both populations.

\section{MATERIALS AND METHODS}

\subsection{Stocks and rearing}

Two populations of Bicyclus anynana were used, one from Malawi (MW) and one from South Africa (SA). The MW laboratory population was established from $80+$ gravid females caught at Nkatha Bay $\left(11^{\circ} 45^{\prime} \mathrm{S}\right.$, 
$34^{\circ} 14^{\prime} \mathrm{E}$ ) in 1988 . The SA laboratory population was established from 70+ gravid females caught in 2006 in False Bay Park of the St. Lucia Wetland Park, KwaZulu Natal $\left(27^{\circ} 58^{\prime} \mathrm{S}, 32^{\circ} 21^{\prime} \mathrm{E}\right)$. Both populations were reared on maize Zea mais, at sufficient numbers to maintain high levels of heterozygosity (at least 400 individuals per generation). Although the MW population has been maintained in the laboratory longer than the SA population, a recent report on 28 microsatellite markers showed overall high levels of heterozygosity and polymorphism for the MW population (van 't Hof et al. 2005).

\subsection{Experimental set-up}

Prior to the experiment, both populations were reared under identical conditions $\left(27^{\circ} \mathrm{C} ; 12 \mathrm{~h}\right.$ light:12 h dark cycle) for one generation to reduce maternal effects.

We chose 3 treatment temperatures to measure reaction norms of the populations: 20,23 and $27^{\circ} \mathrm{C}$. The low $\left(20^{\circ} \mathrm{C}\right)$ and high $\left(27^{\circ} \mathrm{C}\right)$ temperatures are similar to those experienced by larvae of the dry and wet seasonal form, respectively, in the field in Malawi. The addition of an intermediate temperature $\left(23^{\circ} \mathrm{C}\right)$ allowed us to assess potential non-linearity of reaction norms.

The populations were reared at the family and population levels in climate cells with high relative humidity $(\sim 70 \%)$ and a $12 \mathrm{~h}$ light:12 h dark cycle. For the fullsibling family design, offspring of single-mating pairs were divided over the 3 temperatures and reared on maize, each family in a sleeve-like gauze cage. The following traits were measured: larval and pupal development time, pupal weight (as a proxy for adult weight), relative fat content and wing pattern. At the population level, larvae were reared on maize in cages containing $\sim 300$ individuals each. The following traits were measured: larval and pupal development time, pupal weight, starvation resistance and resting metabolic rate. All measurements on live adults were conducted at the same temperature as the rearing temperature.

\subsection{Measurements}

Larval development time and pupal development time were recorded. Pupae were weighed to the nearest $0.1 \mathrm{mg}$ at $1 \mathrm{~d}\left(23\right.$ and $\left.27^{\circ} \mathrm{C}\right)$ or $2 \mathrm{~d}\left(20^{\circ} \mathrm{C}\right)$ after pupation and transferred to individual plastic pots to eclose. At the family level, emerged butterflies were frozen at $-20^{\circ} \mathrm{C}$ within $1 \mathrm{~d}$ after eclosion. For assessment of wing pattern, 3 males and 3 females per temperature were measured from 20 families of the MW population and 18 families of the SA population. At the population level, the butterflies were either randomly selected for live measurements or frozen at $-20^{\circ} \mathrm{C}$ one day after eclosion to determine fat content and wing pattern.

\subsubsection{Relative fat content}

Butterflies were stored at $-20^{\circ} \mathrm{C}$ until measurement. After removal of wings, legs and antennae, the bodies were dried for $48 \mathrm{~h}$ at $40^{\circ} \mathrm{C}$ and weighed to the nearest $0.01 \mathrm{mg}$ to determine dry mass. The fat mass (triglyceride and fatty acid) was then extracted by incubating and shaking (100 rpm) the bodies in a 2:1 dichloridemethane solution at room temperature for $48 \mathrm{~h}$. This step was repeated once with fresh solution, and subsequently the bodies were dried for $24 \mathrm{~h}$ at $40^{\circ} \mathrm{C}$. The fat content was calculated per individual by subtracting the fat-free dry mass from the initial dry mass. Relative fat content was calculated as the percentage of fat mass of the initial dry mass.

\subsubsection{Starvation resistance}

One day after eclosion, butterflies were transferred to cylindrical hanging cages and separated according to sex to prevent mating. Butterflies were numbered individually and kept at a maximum of 15 individuals per cage to minimise density stress. Water-saturated cotton wool was provided ad libitum in the cages to prevent desiccation of the butterflies. Individual deaths were scored daily at a fixed time.

\subsubsection{Resting metabolic rate}

Adult $\mathrm{CO}_{2}$ respirometry $\left(\mathrm{ml} \mathrm{CO} \mathrm{CO}^{-1}\right)$ was measured $1 \mathrm{~d}$ after eclosion, as an index for resting metabolic rate. A Li-Cor LI-6251 $\mathrm{CO}_{2}$ analyzer in a Sable Systems push-through respirometry set-up was used to measure individual respiration. During measurement, butterflies were kept in cylindrical glass containers $(4 \times$ $9 \mathrm{~cm}$, diameter $\times$ length) in a dark, temperature-controlled climate cabinet. Butterflies were measured in the nocturnal stage of their daily cycle to obtain inactive (resting) respiration rates (Pijpe et al. 2007). Data of 2 repeated measurements were analysed using Expedata software (Sable Systems) and averaged to obtain individual $\mathrm{CO}_{2}$ respiration rates.

\subsubsection{Wing pattern}

The ventral surface of one hind wing of each individual was photographed and scanned using a Leica 
DC200 digital camera connected to a Leica MZ12 binocular microscope. The resulting images were analysed with ImagePro software to calculate the following wing pattern elements indicative of seasonal form: (1) surface area of the inner black disk of the fifth eyespot; (2) surface area of the white centre of the fifth eyespot; (3) width of the median band; $(4,5,6)$ Red, green and blue (RGB) spectrum of the dark area in the fourth wing cell (located outside of the median band), respectively; $(7,8,9)$ RGB spectrum of the light area in the fourth wing cell (located in the median band), respectively; and (10) contrast between light and dark in the fourth wing cell (Wijngaarden \& Brakefield 2001). In addition, inter-pupil distance was measured as an estimate of wing size (Beldade \& Brakefield 2002). Analysis showed that wing pattern elements (1-10) did not significantly co-vary with inter-pupil distance and thus were not corrected for size.

\subsection{Statistical analysis}

\subsubsection{Population level}

Data were analysed using 3-way ANOVA with population, temperature and sex as fixed factors. Resting metabolic rate was analysed with pupal weight as a covariate. The wing pattern data (10 measurements) were reduced using a principal component analysis (PCA), and the first 2 components were used for further analysis (see Section 3 for details). Post hoc TukeyKramer Honestly Significant Difference (HSD) tests were used to assess population- and sex-specific responses to temperature where appropriate.

\subsubsection{Family level}

Between and within family variance components and their significance were estimated per population per sex and per temperature, using ANOVAs with family as a random factor. Broad-sense heritabilities were calculated as twice the intra-class correlation coefficient, which is the fraction of total variation due to differences between family groups (Falconer \& Mackay 1996). Genetic correlations $\left(r_{\mathrm{G}}\right)$ across 2 temperatures were estimated using mixed-model ANOVA. In this method, $r_{\mathrm{G}}$ is estimated by dividing the covariance of family means across temperatures by the geometric mean of the between-family variance components (Fry 1992). The covariances of family means across temperatures and their significance were calculated per population per sex, using ANOVAs with temperature as a fixed factor and family as a random factor.

\section{RESULTS}

\subsection{Life history traits}

\subsubsection{Reaction norms}

Fig. 1 shows the reaction norms of pupal weight, relative fat content, starvation resistance and resting metabolic rate in response to temperature for life history and related traits, for each sex. The reaction norm for development time is not shown.

Development time. The factors population $\left(F_{1,872}=\right.$ 162.61, $\mathrm{p}<0.0001)$, temperature $\left(F_{2,872}=6823.84, \mathrm{p}<\right.$ $0.0001)$ and $\operatorname{sex}\left(F_{1,872}=104.5123, \mathrm{p}<0.0001\right)$ had a significant effect on development time. The MW population had a shorter development time than the SA population for each temperature (average difference $=$ $5.8 \%$ ). For both populations, development time differed significantly between rearing temperatures for both sexes $\left(20>23>27^{\circ} \mathrm{C}\right)$. For both populations and each temperature, males had a significantly shorter development time than females (average difference $=$ $5.0 \%)$.

There was a significant interaction between population and temperature $\left(F_{2,872}=31.16, \mathrm{p}<0.0001\right)$, caused by a relatively larger difference between populations at $20^{\circ} \mathrm{C}$ than at the higher temperatures. This might be caused by laboratory adaptation of MW: the stock population was typically reared at $20^{\circ} \mathrm{C}$, which may have favoured a relatively faster development time at this temperature over time.

Pupal weight. There was a significant effect of population $\left(F_{1,869}=185.92, \mathrm{p}<0.0001\right)$, temperature $\left(F_{2,869}=\right.$ 4.42, $\mathrm{p}=0.0123)$ and $\operatorname{sex}\left(F_{1,869}=964.43, \mathrm{p}<0.0001\right)$ on pupal weight (Fig. 2A). For both sexes, the SA population had a lower pupal weight than the MW population for all temperatures (average difference $=10.3 \%$ ). There was no interaction between population and temperature, indicating a similar plasticity response of the populations to temperature. Per population and per sex, between-temperature differences were not significant in post hoc tests $\left(20=23=27^{\circ} \mathrm{C}\right)$, although there was a consistent trend for both sexes and populations $\left(20>23>27^{\circ} \mathrm{C}\right)$. Pupal weight was consistently lower in males than in females for both populations (average difference $=24.7 \%$ ).

Relative fat content. The factors population $\left(F_{1,654}=\right.$ 112.87, $\mathrm{p}<0.0001)$, temperature $\left(F_{2,654}=14.8219, \mathrm{p}<\right.$ $0.0001)$ and $\operatorname{sex}\left(F_{1,654}=126.73, \mathrm{p}<0.0001\right)$ had $\mathrm{a}$ significant effect on fat content (Fig. 2B). Fat content was consistently lower in the SA population than in the MW population for both males and females. The variation explained by temperature was relatively small compared to population and sex. Significant interactions between temperature and population $\left(F_{2,654}=3.37, \mathrm{p}=0.035\right)$, and 

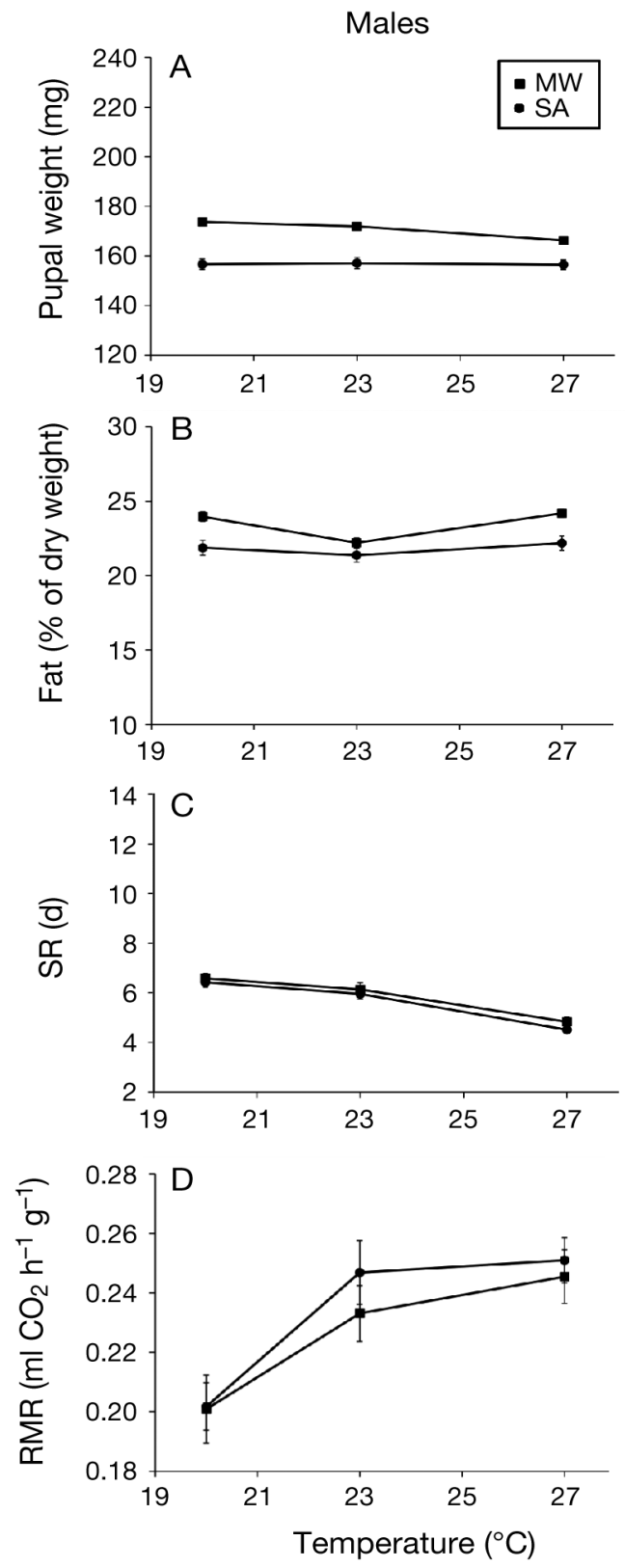

Females
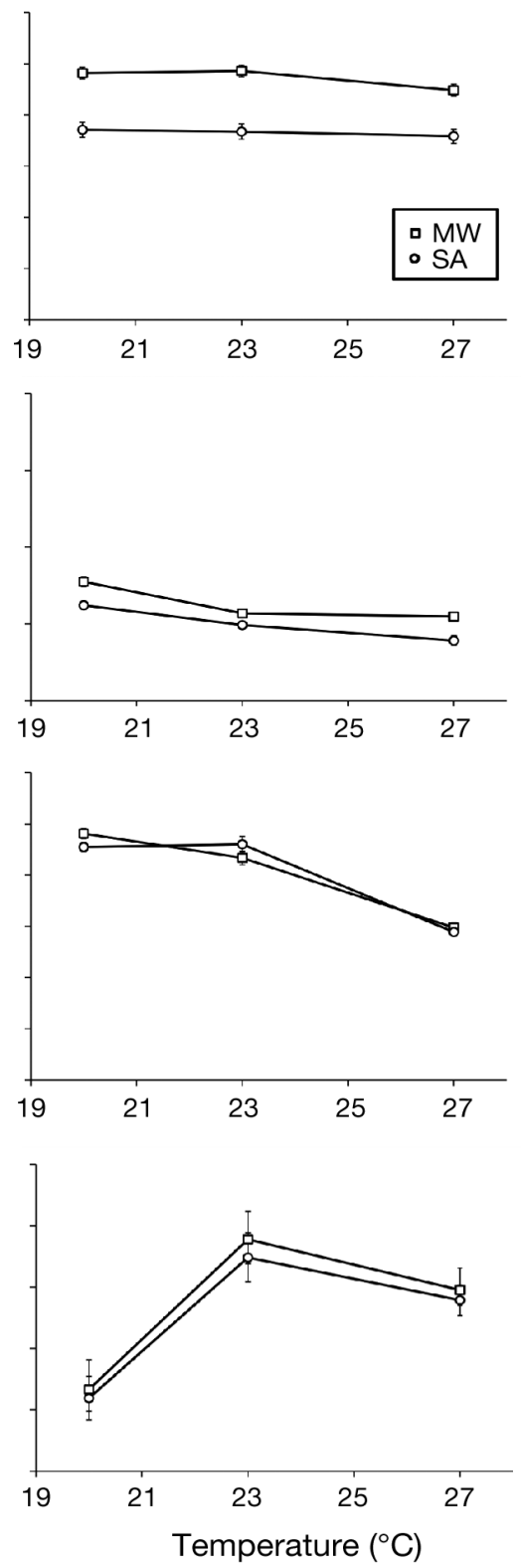

Fig. 1. Bicyclus anynana. Thermal reaction norms of life history traits: (A) pupal weight; (B) relative fat content; (C) starvation resistance (SR); and (D) resting metabolic rate (RMR). MW: Malawi; SA: South Africa. Error bars: \pm 1 SE

temperature and sex $\left(F_{2,654}=17.6235, \mathrm{p}<0.0001\right)$ indicated population- and sex-specific responses to temperature. Post hoc tests revealed differences in reaction norm shape between populations for both males (MW: $20=23>27^{\circ} \mathrm{C}$; SA: $20=23=27^{\circ} \mathrm{C}$ ) and females (MW: $20>23=27^{\circ} \mathrm{C} ; \mathrm{SA}: 20=23=27^{\circ} \mathrm{C}$ ).

Starvation resistance. Temperature had a significant negative effect on starvation resistance $\left(F_{2,789}=182.76\right.$, $\mathrm{p}<0.0001)$. Populations showed no significant differences in their starvation resistance reaction norms, and there was no significant interaction between population and temperature (Fig. 1C). There was a significant effect of $\operatorname{sex}\left(F_{1,789}=1237.50, \mathrm{p}<0.0001\right)$, with females being on average $78.5 \%$ more starvation resistant than males. A significant interaction of sex and temperature $\left(F_{2,789}=21.64, \mathrm{p}<0.0001\right)$ indicated sex-specific responses to temperature. Post hoc tests for separate sexes revealed a significant difference between 23 and $27^{\circ} \mathrm{C}$ but not between 20 and $23^{\circ} \mathrm{C}$ for females $(20=$ $23>27^{\circ} \mathrm{C}$ ). For males, there were significant differences in starvation resistance between each temperature $\left(20>23>27^{\circ} \mathrm{C}\right)$, although the difference between 20 and $23^{\circ} \mathrm{C}$ was much smaller than between 23 and $27^{\circ} \mathrm{C}$. 

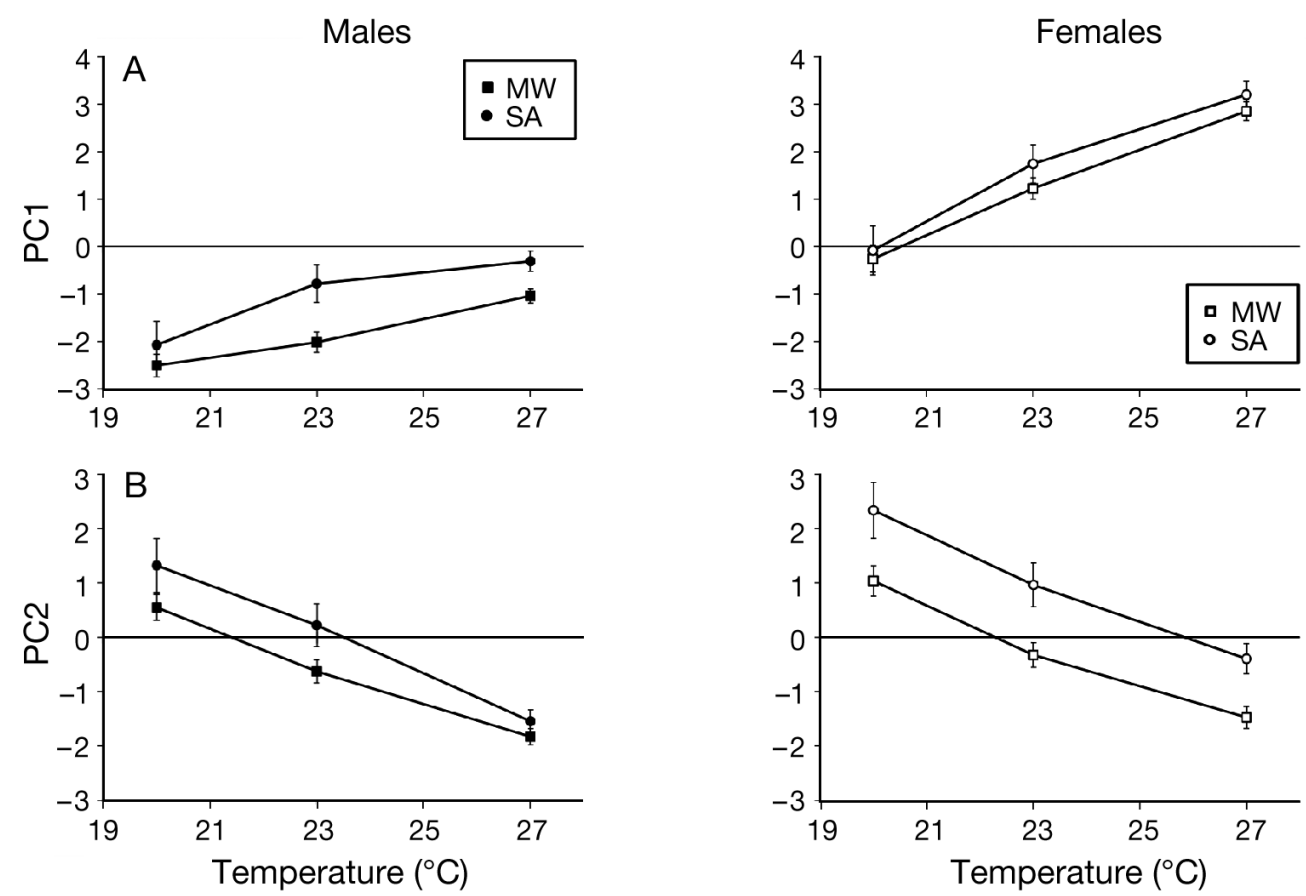

Fig. 2. Bicyclus anynana. Thermal reaction norms of first and second principal component of 10 wing pattern elements. (A) PC1; (B) PC2. MW: Malawi; SA: South Africa. Error bars represent $\pm 1 \mathrm{SE}$

Resting metabolic rate. There was a significant positive effect of temperature on resting metabolic rate $\left(F_{2,743}=30.82, \mathrm{p}>0.0001\right)$, but not of population or sex (Fig. 1D). There were no significant interactions between factors. A post hoc test revealed a significant difference between 20 and $23^{\circ} \mathrm{C}$, but not between $23^{\circ} \mathrm{C}$ and $27^{\circ} \mathrm{C}\left(20<23=27^{\circ} \mathrm{C}\right)$.

\subsubsection{Heritabilities and cross-temperature correlations}

Table 1 gives broad-sense heritabilities for development time and pupal weight for each population, sex and temperature, as well as cross-temperature correlations between 20 and $27^{\circ} \mathrm{C}, 20$ and $23^{\circ} \mathrm{C}$, and 23 and $27^{\circ} \mathrm{C}$. All heritabilities were significant and ranged from moderate to high. Heritabilities were similar for the 2 traits, and showed no clear or consistent differences between populations, sexes or temperatures. All correlations were positive and significantly different from zero.

\subsection{Wing pattern}

Table 2 gives the first 2 principal components (PC1 and PC2) of 10 wing pattern measurements (size and colour of pattern elements) associated with seasonality. Combined, they explained about $81 \%$ of the variation in the data. The first eigenvector had the highest load- ings for the bright colours, while the second eigenvector showed the highest loadings for the eyespot size elements. Both eigenvectors had similar loadings for dark colour and contrast. Note that the sign of the band measurement is an artefact of the way the trait is measured: with increasing band size, the value of the variable decreases.

\subsubsection{Reaction norms}

Fig. 2 shows reaction norms of the 2 populations for PC1 and PC2 for each sex. There was a significant effect of the factors population $\left(F_{1,865}=29.45, \mathrm{p}<\right.$ $0.0001)$, temperature $\left(F_{2,865}=171.77, \mathrm{p}<0.0001\right)$ and $\operatorname{sex}\left(F_{1,865}=750.98, \mathrm{p}<0.0001\right)$ on PC1. Significant interactions between temperature and $\operatorname{sex}\left(F_{2,865}=\right.$ $18.75, \mathrm{p}<0.0001)$, and population and $\operatorname{sex}\left(F_{1,865}=\right.$ $4.51, \mathrm{p}=0.034$ ) indicated a sex- and population-specific response to temperature. Subsequent post hoc testing per sex revealed no significant differences between the populations in the response of females $\left(20>23>27^{\circ} \mathrm{C}\right)$. Males differed significantly between populations for the temperatures 23 and $27^{\circ} \mathrm{C}$, and showed a different pattern in response to temperature (MW: $20=23<27^{\circ} \mathrm{C}$; SA: $20<23=27^{\circ} \mathrm{C}$ ).

The factors population $\left(F_{1,865}=219.94, \mathrm{p}<0.0001\right)$, temperature $\left(F_{2,865}=588.82, \mathrm{p}<0.0001\right)$ and sex $\left(F_{1,865}=116.18, \mathrm{p}<0.0001\right)$ had a significant effect on $\mathrm{PC} 2$. A significant interaction between temperature 
Table 1. Bicyclus anynana. Broad-sense heritabilities and cross-temperature correlations $\left(r_{\mathrm{G}}\right)$ for development time and pupal weight. MW: Malawi;

SA: South Africa; F: female; M: male. ${ }^{*} \mathrm{p}<0.05_{;}{ }^{* *} \mathrm{p}<0.01{ }^{* * *} \mathrm{p}<0.001$

\begin{tabular}{|c|c|c|c|c|c|c|c|}
\hline \multirow[b]{2}{*}{ Line } & \multirow[b]{2}{*}{ Sex } & \multicolumn{3}{|c|}{ - Heritability } & \multicolumn{3}{|c|}{ Cross-temperature correlation } \\
\hline & & $20^{\circ} \mathrm{C}$ & $23^{\circ} \mathrm{C}$ & $27^{\circ} \mathrm{C}$ & $20-27^{\circ} \mathrm{C}$ & $20-23^{\circ} \mathrm{C}$ & $23-27^{\circ} \mathrm{C}$ \\
\hline \multicolumn{8}{|c|}{ Development time } \\
\hline \multirow[t]{2}{*}{ MW } & $\mathrm{F}$ & $0.27^{* * *}$ & $0.49^{* * *}$ & $0.36^{* * *}$ & $0.61^{* * *}$ & $0.76^{* * *}$ & $0.85^{* * *}$ \\
\hline & M & $0.41^{* * *}$ & $0.49^{* * *}$ & $0.24^{* *}$ & $0.64^{* * *}$ & $0.77^{* * *}$ & $1.00^{* * *}$ \\
\hline \multirow[t]{2}{*}{ SA } & $\mathrm{F}$ & $0.40^{* * *}$ & $0.49^{* * *}$ & $0.46^{* * *}$ & $0.72^{* * *}$ & $0.24^{* * *}$ & $0.68^{* * *}$ \\
\hline & $\mathrm{M}$ & $0.22^{*}$ & $0.78^{* * *}$ & $0.75^{* * *}$ & $0.74^{* * *}$ & $0.49^{* * *}$ & $0.70^{* * *}$ \\
\hline \multicolumn{8}{|c|}{ Pupal weight } \\
\hline \multirow[t]{2}{*}{ MW } & $\mathrm{F}$ & $0.58^{* * *}$ & $0.73^{* * *}$ & $0.72^{* * *}$ & $0.73^{* * *}$ & $0.95^{* * *}$ & $0.81^{* * *}$ \\
\hline & $\mathrm{M}$ & $0.44^{* * *}$ & $0.65^{* * *}$ & $0.28^{* * *}$ & $0.67^{* * *}$ & $0.89^{* * *}$ & $0.83^{* * *}$ \\
\hline \multirow[t]{2}{*}{ SA } & $\mathrm{F}$ & $0.40^{* * *}$ & $0.41^{* * *}$ & $0.64^{* * *}$ & $0.67^{* * *}$ & $0.69^{* * *}$ & $0.95^{* * *}$ \\
\hline & $\mathrm{M}$ & $0.53^{* * *}$ & $0.41^{* * *}$ & $0.78^{* * *}$ & $0.88^{* * *}$ & $0.74^{* * *}$ & $0.95^{* * *}$ \\
\hline
\end{tabular}

and population $\left(F_{2,865}=3.94, \mathrm{p}=0.02\right)$ meant there was a difference in plasticity response to temperature. Post hoc testing showed a significant difference between populations for each temperature for both sexes, except for the males at $27^{\circ} \mathrm{C}$. Both populations and both sexes responded in a similar pattern to temperature $\left(20>23>27^{\circ} \mathrm{C}\right)$.

\subsubsection{Heritabilities and cross-temperature correlations}

Heritabilities and cross-temperature correlations between 20 and $27^{\circ} \mathrm{C}, 20$ and $23^{\circ} \mathrm{C}$, and 23 and $27^{\circ} \mathrm{C}$ for PC1 and PC2 for each population, sex and temperature are shown in Table 3 . The range of heritabilities was moderate to high, mostly very high (>0.8) and, with the exception of a few cases, significant. Heritabilities were slightly higher for PC1 than PC2, with no notable differences between populations, sexes or temperatures. All correlations were positive and differed significantly from zero.

Table 2. Bicyclus anynana. Loadings on PC1 and PC2 for 10 wing pattern measurements, and the percentage of variation explained by each principal component

\begin{tabular}{|lrr|}
\hline Trait & PC1 & PC2 \\
\hline 5th spot bright area & 0.24 & -0.39 \\
5th spot dark area & 0.14 & -0.48 \\
Distance node-band & -0.11 & 0.46 \\
Dark colour R & 0.34 & 0.31 \\
Dark colour G & 0.35 & 0.31 \\
Dark colour B & 0.30 & 0.36 \\
Bright colour R & 0.40 & -0.02 \\
Bright colour G & 0.41 & -0.01 \\
Bright colour B & 0.40 & -0.02 \\
Dark-bright contrast & 0.30 & -0.29 \\
\% explained & 57.03 & 23.62 \\
\hline
\end{tabular}

\section{DISCUSSION}

\subsection{Reaction norms}

An important analytical concept in the study of phenotypic plasticity is the reaction norm, i.e. the phenotypic expression of a genotype across an environmental range (Schlichting \& Pigliucci 1998). By measuring the reaction norms of geographically different populations under the same range of conditions ('common garden' approach), the level of genetic divergence between the populations for the plasticity response can be determined. A difference in the slope or shape of the reaction norm corresponds to a genetic difference underlying the plastic response to environmental conditions (genotype-environment interaction).
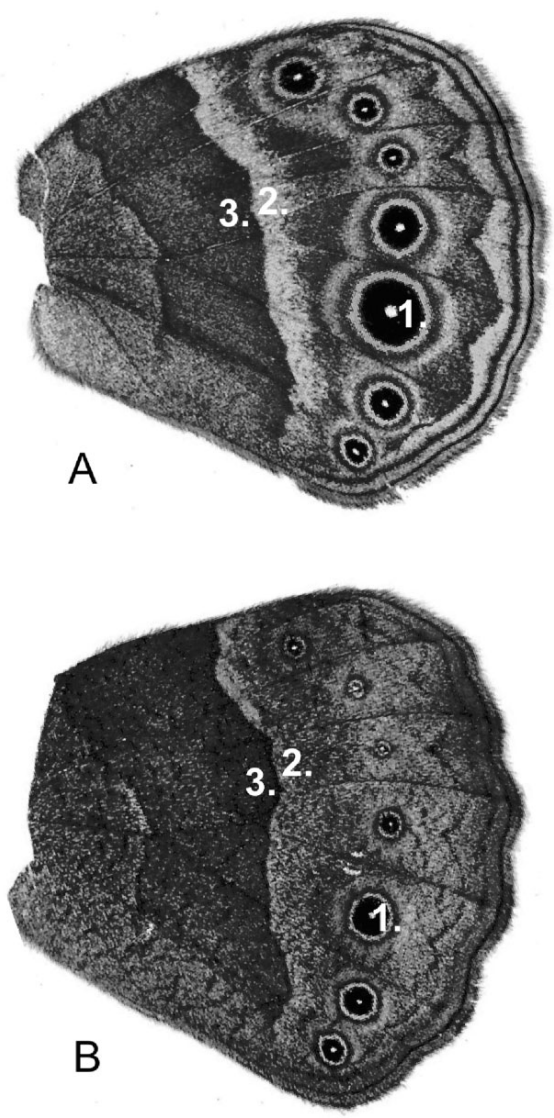

Fig. 3. Bicyclus anynana. Hind wing of female B. anynana in the (A) wet season and (B) dry season. Numbers indicate wing pattern elements that were used to measure plasticity: (1) large eyespot of the hind wing; (2) light area of median band in fourth wing cell; and (3) area used to measure dark colour in fourth wing cell (located outside of the median band) 
Table 3. Bicyclus anynana. Broad-sense heritabilities and cross-temperature correlations $\left(r_{\mathrm{G}}\right)$ for PC1 and PC2 of 10 wing pattern measurements. MW: Malawi; SA: South Africa; F: female; M: male. ${ }^{*}: \mathrm{p}<0.05_{;}{ }^{* *}: \mathrm{p}<0.01{ }^{* * *}: \mathrm{p}<0.001$

\begin{tabular}{|c|c|c|c|c|c|c|c|}
\hline \multirow[b]{2}{*}{ Line } & \multirow[b]{2}{*}{ Sex } & \multicolumn{3}{|c|}{$\ldots$ Heritability $\_$} & \multicolumn{3}{|c|}{ Cross-temperature correlation } \\
\hline & & $20^{\circ} \mathrm{C}$ & $23^{\circ} \mathrm{C}$ & $27^{\circ} \mathrm{C}$ & $20-27^{\circ} \mathrm{C}$ & $20-23^{\circ} \mathrm{C}$ & $23-27^{\circ} \mathrm{C}$ \\
\hline \multicolumn{8}{|l|}{ PC1 } \\
\hline \multirow[t]{2}{*}{ MW } & F & $0.92^{* * *}$ & $1.00^{* * *}$ & $0.82^{* * *}$ & $0.85^{* * *}$ & $0.91^{* * *}$ & $1.01^{* * *}$ \\
\hline & $\mathrm{M}$ & $0.83^{* * *}$ & $0.88^{* * *}$ & 0.39 & $0.81^{* * *}$ & $0.83^{* * *}$ & $1.07^{* * *}$ \\
\hline \multirow[t]{2}{*}{ SA } & $\mathrm{F}$ & $1.00^{* * *}$ & $1.00^{* * *}$ & $1.00^{* * *}$ & $0.92^{* * *}$ & $0.95^{* * *}$ & $0.93^{* * *}$ \\
\hline & M & $0.92^{*}$ & $1.00^{* * *}$ & $1.00^{* * *}$ & $0.97^{* * *}$ & $0.98^{* * *}$ & $1.01^{* * *}$ \\
\hline \multicolumn{8}{|l|}{ PC2 } \\
\hline \multirow[t]{2}{*}{ MW } & F & $0.88^{* * *}$ & 0.35 & $0.49^{*}$ & $0.65^{* * *}$ & $1.00^{* * *}$ & $0.71^{* * *}$ \\
\hline & M & $0.72^{* *}$ & $0.56^{*}$ & $0.14^{* * *}$ & $0.85^{* * *}$ & $0.76^{* * *}$ & $2.06^{* * *}$ \\
\hline \multirow[t]{2}{*}{ SA } & F & $0.82^{* * *}$ & $0.77^{* *}$ & $1.00^{* * *}$ & $0.77^{* * *}$ & $0.96^{* * *}$ & $0.82^{* * *}$ \\
\hline & M & 0.40 & $0.46^{*}$ & $0.58^{* *}$ & $0.91^{* * *}$ & $0.52^{* * *}$ & $0.90^{* * *}$ \\
\hline
\end{tabular}

\subsubsection{Development time, weight and fat content}

For both populations, development time decreased considerably with increasing temperature; this is widely observed for ectotherms and is generally viewed as nonadaptive plasticity (Nylin \& Gotthard 1998). Both weight and fat content showed no clear directional pattern in developmental plasticity responses to temperature (Fig. 1A,B). It is commonly found that insects developing at lower temperatures become larger (Sibly \& Atkinson 1994). While there was a trend showing increasing weight with decreasing temperature for both populations, these differences were not significant despite large sample sizes. Hence there does not seem to be a noteworthy effect of developmental temperature on size at maturity, at least not for the range of temperatures we used here. The shape of reaction norms for fat content differed between the populations. For SA, there was no effect of developmental temperature on fat content, while MW showed small but significant effects of temperature that differed between the sexes. Development time was consistently higher, and weight and fat content lower, for the SA population than the MW population for both sexes. We are cautious to account for these differences between populations in terms of adaptive differentiation because these traits might have been influenced by differences in food plant adaptation between the populations. Moreover, as the effect of temperature on development time may be entirely non-adaptive, and weight and fat content show little to no response to temperature, these traits may be of minor relevance in the context of the present study, i.e. concerning adaptive plasticity in response to temperature.

\subsubsection{Starvation resistance and resting metabolic rate}

Starvation resistance is a crucial trait in surviving periods of food shortage for many species. Previous work on Bicyclus anynana has shown that starvation resistance is a plastic trait highly dependent on both pre-adult and adult temperatures (Pijpe et al. 2007). Confirming prior reports, we found a strong effect of temperature, with increasing starvation resistance at lower temperatures, and females being more resistant to starvation than males (Fig. 1C). Interestingly, there was no population differentiation for the starvation resistance reaction norms between populations. Males and females of both the SA and MW populations showed a clear decrease in starvation resistance for the higher temperature. In other species, findings on population comparisons for starvation resistance vary. For Drosophila spp., for instance, there are reports of latitudinal variation for populations in India (Hoffmann \& Harshman 1999) and North America (Schmidt et al. 2005), and altitudinal variation (Sørensen et al. 2005), while other studies found little or no level of differentiation at the geographic level (Robinson et al. 2000, Hoffmann et al. 2001).

Resting metabolic rate probably plays an important role in mediating survival under starvation in Bicyclus anynana (Pijpe et al. 2007) and other species such as Drosophila (e.g. Rion \& Kawecki 2007). Similarly to starvation resistance, resting metabolic rate shows developmental plasticity in response to temperature in B. anynana (Pijpe et al. 2007, V. Oostra et al. unpubl. data). For both populations we observed a significant increase in resting metabolic rate for high temperature compared to the intermediate and low temperature (Fig. 1D). As with starvation resistance, we found no geographic differentiation in thermal reaction norm between the populations.

\subsubsection{Wing pattern}

Wing pattern is the most thoroughly studied seasonally plastic trait in Bicyclus anynana, and the adaptive benefit of the cryptic form in the dry season has been previously demonstrated (Lyytinen et al. 2004, Brakefield \& Frankino 2009). Fig. 3 shows a wet season and a dry season form of a female $B$. anynana hind wing, with the measured areas indicated. Our results show a strong effect of developmental temperature on wing pattern for both PC1 and PC2 (Fig. 2), confirming the extensive plastic response of wing pattern to developmental temperature in this species. PC1 explained the larger part of the variation in the data (57\%) and had the highest loadings of the colour measurements 
(Table 2). Wing colour in B. anynana differs among the sexes and seasonal forms. Males are darker than females, and the dry season form of both males and females is generally darker than the wet season form. This is evident in the reaction norm of PC1, which shows a strong response of temperature and clear sex differences (Fig. 2A). The 2 male populations differed significantly for the males, with SA males developing towards a more wet season form wing pattern at lower temperatures relative to MW males. Although 2 populations are not sufficient to infer directional selection, the observed pattern is concordant with the overall lower temperatures in South Africa compared to Malawi. Females showed a similar but non-significant trend.

PC2 accounted for a smaller part of the variation $(23.6 \%)$ and had the highest loadings of the size elements (e.g. eyespot size, Table 2). The size elements of the wings were strongly linked to seasonal form, with large eyespots and a clear white band in the wet season, as opposed to much smaller or absent eyespots and band in the dry season. There were also sex differences for the size elements, which were larger in females than in males, but these were not as pronounced as the colour differences. Both males and females showed inter-population differences for $\mathrm{PC} 2$, but in the opposite direction of PC1, resulting in overall higher values for the SA population than the MW population (Fig. 2B). This, in turn, indicates that the size elements are smaller (because the loadings of the size elements were negative on PC2) for the SA population. Eyespot size is expected to play a role in mate choice and to be under sexual selection (Breuker \& Brakefield 2002, Robertson \& Monteiro 2005), which could possibly account for the observed population differences.

\subsubsection{Synthesis}

To summarise, the populations showed very similar thermal reaction norms for the life history traits and resting metabolic rate, especially for those traits with a clear plastic response to temperature. In contrast, wing pattern showed more differentiation, in the intercept as well as the shape of the reaction norms. In order to identify the extent of population differentiation relative to thermal plasticity response, we performed PCAs on the life history traits, including resting metabolic rate (Fig. 4A), and on wing pattern (Fig. 4B). In the PCA of life history traits, the effects of temperature and sex were large, while the popula-

.

tions were grouped closely for each sex and temperature. The wing pattern PCA also showed a large effect of temperature and sex, but in comparison the separation between the populations along the PC axes was much larger for wing pattern than for the life history traits. Although studies on geographic variation using a range of temperatures are rare, we know of one such study that includes both life history traits and morphological wing traits (wing length and area) in Drosophila melanogaster (van 't Land et al. 1999). In concordance
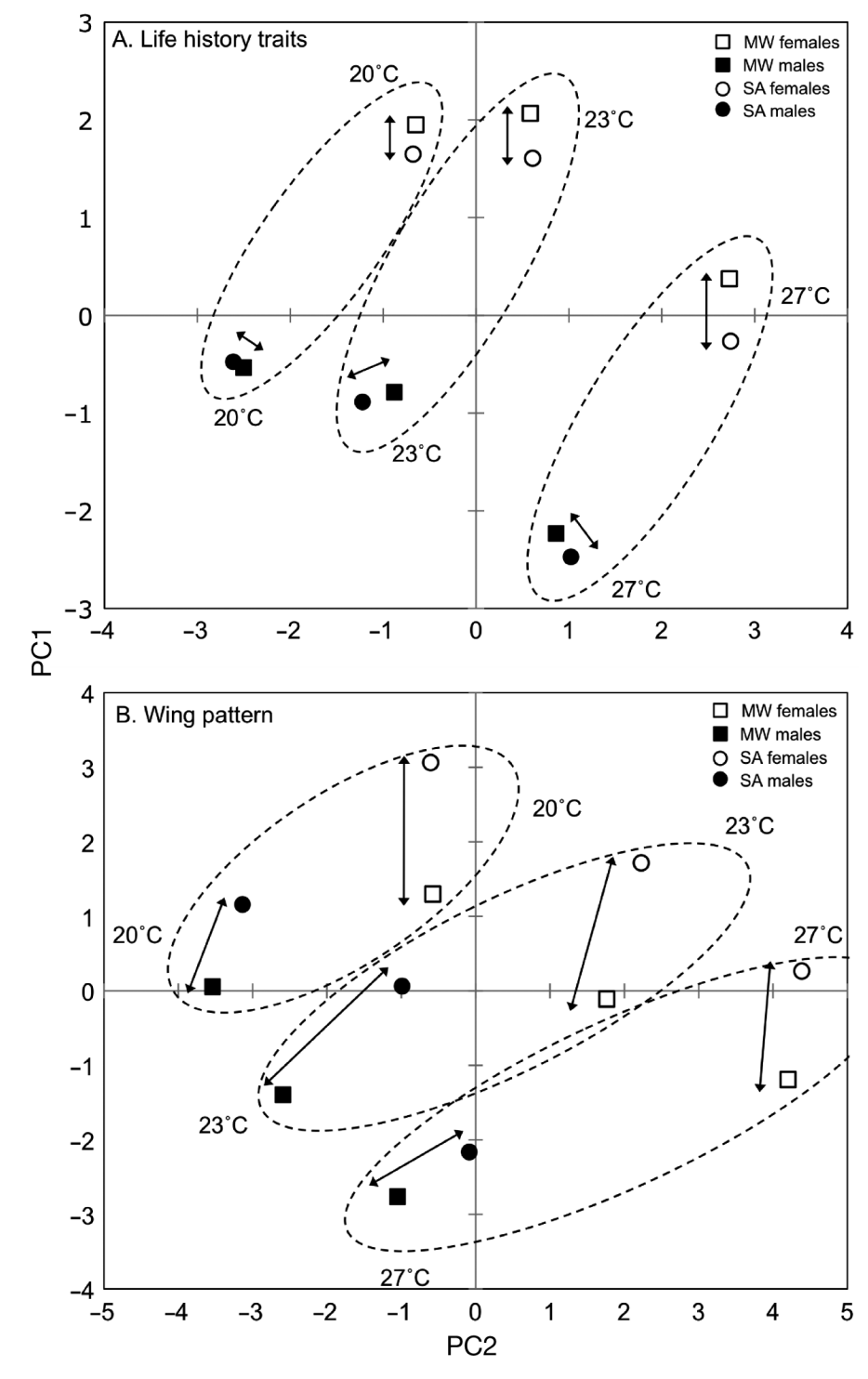

Fig. 4. Bicyclus anynana. Principal component analyses on the averages of life history traits and wing pattern per temperature, sex and population. Dotted lines indicate temperature groups. Arrows indicate distances between populations. (A) Life history traits: larval development time, pupal development time, pupal weight, relative fat content and starvation resistance. PC1 and PC2 explained $91.3 \%$ of the variation. (B) Wing pattern: 10 wing measurements (see Section 2). PC1 and PC2 explained $98.1 \%$ of the variation. MW: Malawi; SA: South Africa 
with our findings, relatively small population differences were found between the reaction norms of life history traits compared to morphological wing traits (van 't Land et al. 1999).

Finally, the overall non-linearity of the reaction norms corresponded well to the polyphenic nature of Bicyclus anynana in the wild (Brakefield \& Reitsma 1991). Especially for starvation resistance and resting metabolic rate, the shape of the reaction norms suggests a discontinuous pattern. This was indeed confirmed for several traits by an experiment including more temperature treatments (V. Oostra et al. unpubl. data), indicating that the transition between development into either dry- or wet-season form occurs in a relatively narrow temperature window, which is often the case for polyphenic species (Nijhout 2003).

\subsection{Heritabilities and cross-environment correlations}

Genetic change of the plasticity response of a trait by selection requires that the trait is heritable and that there is genetic variation for plasticity (variation in slope of the reaction norms) (Via \& Lande 1985, de Jong 1995). To gain insight into the potential of organisms to adapt to climate change, it is thus important to study the heritability of traits (Pertoldi \& Bach 2007, Chown et al. 2010). In the present study, we estimated heritabilities using a full-sibling family design, resulting in broad-sense heritabilities that include both additive and non-additive genetic variance. Therefore, broad-sense heritabilities generally represent an overestimation of the heritable variation of traits (Roff 1997). Our results show considerably higher heritabilities for wing pattern (Table 3) than for development time and weight (Table 1) in both populations. This corresponds to the general finding that life history traits have lower heritabilities than morphological traits. Consequently, it is often assumed that life history traits have less genetic variation and evolve more slowly in response to directional selection because they are more closely linked to fitness (Roff \& Mousseau 1987). This would be in agreement with our findings and could explain why we observed substantially more population differentiation for wing pattern than for the life history traits. However, the comparison between heritabilities of life history and morphological traits should be made with caution. When taking into account the different components comprising the trait variance $\left(V_{\mathrm{P}}\right)$, the low heritabilities of fitness-related traits can often be explained by their high residual variation $\left(\mathrm{V}_{\mathrm{R}}\right.$ : non-additive genetic and environmental factors). The additive genetic variance $\left(\mathrm{V}_{\mathrm{A}}\right)$ would be a more precise measure to compare the selective response potential between traits
(Houle 1992), but our experimental set-up did not allow for estimating narrow-sense heritability.

The trait values of a plastic trait for different environments can be considered as separate, genetically correlated characters (Falconer \& Mackay 1996). These cross-environment correlations can be used as a measure of variation for the plastic trait, or the level of genotype-environment interaction. When the crossenvironment correlation between genotypes is +1 , the slopes of the reaction norms run parallel and there is no genotype-environment interaction. A correlation of $<+1$ indicates the presence of genetic variation for the plasticity response of the trait (Pigliucci 2005). Our data show high cross-temperature correlations for both life history traits (Table 1) and wing pattern (Table 3) for both populations. All correlations were lower than +1 , indicating the presence of genetic variation for the plasticity response of the traits and the potential for adaptation by selection.

\subsection{Developmental plasticity and adult acclimation}

In order to unravel the complexity of phenotypic plasticity, it is important to distinguish between developmental plasticity (phenotypic change induced during development) and adult acclimation (reversible or flexible plasticity during the adult stage). A recent review concluded that many studies aimed at examining adult acclimation actually assessed the consequences of the developmental environment (Wilson \& Franklin 2002), and so far only a few studies have examined the relative contributions of the 2 forms of plasticity in a single experiment (e.g. Fischer et al. 2003, Terblanche \& Chown 2006). For Bicyclus anynana, both developmental plasticity and adult acclimation are important in coping with seasonality (Fischer et al. 2003, Brakefield \& Frankino 2009). Some traits, for example wing pattern and body size, are developmentally plastic, but fixed during the adult stage. Other traits, including resting metabolic rate and egg size, show both forms of plasticity. The initial state of these traits in early adult life depends on the developmental environment, but can be changed by acclimation depending on the adult environment. For example, egg size is initially dependent on developmental temperature, with females reared at cool temperatures producing fewer and larger eggs than females reared at warm temperatures. Cross-transferring females among temperatures can reverse this effect by acclimation over a period of $\sim 10 \mathrm{~d}$ (Fischer et al. 2003). In the context of adaptive phenotypic plasticity, developmental plasticity serves as a prediction of the adult environment based on pre-adult conditions. Adult acclimation can thus be seen as the organism's ability 
to fine-tune its phenotype to the actual and potentially variable environmental conditions (beneficial acclimation hypothesis, Leroi et al. 1994).

Our results reveal an interesting pattern when taking both forms of plasticity into account. Of the traits that showed a clear developmental response to temperature, we found geographic variation in the thermal reaction norm of the irreversible trait wing pattern, but no visible differentiation in starvation resistance and resting metabolic rate, both of which are traits that can be influenced by acclimation during adult life. Moreover, in a different experiment we measured developmental plasticity of egg size using the same 2 populations and developmental temperatures (data not shown). We found no population differences between their thermal reaction norms for egg size. Phenotypic plasticity may buffer environmental variation, thus shielding the genetic response to selection (Falconer \& Mackay 1996, West-Eberhard 2003). This, in turn, can slow down or prevent geographic differentiation. Our data suggest that, likewise, adult acclimation may shield developmental plasticity from evolutionary change.

\section{CONCLUSIONS}

Our study on geographic variation in the polyphenic response to temperature in B. anynana revealed a population specific response in wing pattern plasticity to developmental temperature. Therefore, when considering present-day climate change, a rise in temperature could consequently result in a phenotypic mismatch of wing pattern to season. High heritabilities and genetic variation for the plasticity response of wing pattern indicate a potential for adaptation. Despite the large difference in latitude between the populations and the differences in regional climate, we found little to no geographic variation for the life history traits that showed a clear plasticity response to developmental temperature. Furthermore, there was no geographic variation in the plasticity response of the traits that can be changed by acclimation in the adult stage. This indicates that adult acclimation plays a major role in coping with regional climate. Whether or not there is geographic variation in adult acclimation responses to temperature will make an interesting topic for future research.

Acknowledgements. We thank N. Wurzer and M. Lavrijsen for the plant rearing, and J. Ellens for help in performing the experiment. Furthermore, we acknowledge the European Science Foundation's programmes ThermAdapt and ConGen. This work was funded by the Earth and Life Sciences programme of the Netherlands Organization for Scientific Research (Grant no. 814.01.012).

\section{LITERATURE CITED}

Beldade P, Brakefield PM (2002) The genetics and evo-devo of butterfly wing patterns. Nat Rev Genet 3:442-452

Brakefield PM, Frankino WA (2009) Polyphenisms in Lepidoptera: multidisciplinary approaches to studies of evolution. In: Whitman DW, Ananthakrishnan TN (eds) Phenotypic plasticity in insects: mechanisms and consequences. Science Publishers, Plymouth, p 121-152

Brakefield PM, Larsen TB (1984) The evolutionary significance of dry and wet season forms in some tropical butterflies. Biol J Linn Soc 22:1-12

Brakefield PM, Reitsma N (1991) Phenotypic plasticity, seasonal climate and the population biology of Bicyclus butterflies (Satyridae) in Malawi. Ecol Entomol 16:291-303

> Brakefield PM, Pijpe J, Zwaan BJ (2007) Developmental plasticity and acclimation both contribute to adaptive responses to alternating seasons of plenty and of stress in Bicyclus butterflies. J Biosci 32:465-475

> Breuker CJ, Brakefield PM (2002) Female choice depends on size but not symmetry of dorsal eyespots in the butterfly Bicyclus anynana. Proc R Soc Lond B 269:1233-1239

Chown SL, Hoffmann AA, Kristensen TN, Angilletta MJ Jr, Stenseth NC, Pertoldi C (2010) Adapting to climate change: a perspective from evolutionary physiology. Clim Res 43:3-15

de Jong G (1995) Phenotypic plasticity as a product of selection in a variable environment. Am Nat 145:493-512

Dixon AFG, Kindlmann P (1999) Population dynamics of aphids. In: Dempster JP, MacLean IFG (eds) Insect populations. Kluwer Academic Publishers, Dordrecht, p 207-230

Endler JA (1986) Natural selection in the wild. Princeton University, Princeton, NJ

Falconer DS, Mackay TFC (1996) Introduction to quantitative genetics. Longman, Harlow

> Fischer K, Karl I (2010) Exploring plastic and genetic responses to temperature variation using copper butterflies. Clim Res 43:17-30

- Fischer K, Eenhoorn E, Bot ANM, Brakefield PM, Zwaan BJ (2003) Cooler butterflies lay larger eggs: developmental plasticity versus acclimation. Proc R Soc Lond B 270: 2051-2056

> Fry JD (1992) The mixed-model analysis of variance applied to quantitative genetics: biological meaning of the parameters. Evolution 46:540-550

Gotthard K, Nylin S (1995) Adaptive plasticity and plasticity as an adaptation: a selective review of plasticity in animal morphology and life-history. Oikos 74:3-17

Hoffmann AA, Harshman LG (1999) Desiccation and starvation resistance in Drosophila: patterns of variation at the species, population and intrapopulation levels. Heredity 83:637-643

Hoffmann AA, Hallas R, Sinclair C, Mitrovski P (2001) Levels of variation in stress resistance in Drosophila among strains, local populations, and geographic regions: patterns for desiccation, starvation, cold resistance, and associated traits. Evolution 55:1621-1630

Houle D (1992) Comparing evolvability and variability of quantitative traits. Genetics 130:195-204

Kingsolver JG (1996) Experimental manipulation of wing pattern and survival in western white butterflies. Am Nat 147:296-306

- Kooi RE, Brakefield PM (1999) The critical period for wing pattern induction in the polyphenic tropical butterfly $B i$ cyclus anynana (Satyrinae). J Insect Physiol 45:201-212

> Leroi AM, Bennett AF, Lenski RE (1994) Temperature acclimation and competitive fitness: an experimental test of the 
beneficial acclimation assumption. Proc Natl Acad Sci USA 91:1917-1921

Lyytinen A, Brakefield PM, Lindstrom L, Mappes J (2004) Does predation maintain eyespot plasticity in Bicyclus anynana? Proc R Soc Lond B 271:279-283

Nijhout HF (2003) Development and evolution of adaptive polyphenisms. Evol Dev 5:9-18

Nylin S, Gotthard K (1998) Plasticity in life-history traits. Annu Rev Entomol 43:63-83

Parmesan C (2006) Ecological and evolutionary responses to recent climate change. Annu Rev Ecol Evol Syst 37: 637-669

Pertoldi C, Bach LA (2007) Evolutionary aspects of climateinduced changes and the need for multidisciplinarity. J Therm Biol 32:118-132

Pigliucci M (2005) Evolution of phenotypic plasticity: Where are we going now? Trends Ecol Evol 20:481-486

Pijpe J, Brakefield PM, Zwaan BJ (2007) Phenotypic plasticity of starvation resistance in the butterfly Bicyclus anynana. Evol Ecol 21:589-600

Rezende EL, Balanyà J, Rodríguez-Trelles F, Rego C and others (2010) Climate change and chromosomal inversions in Drosophila subobscura. Clim Res 43:103-114

Rion S, Kawecki TJ (2007) Evolutionary biology of starvation resistance: what we have learned from Drosophila. J Evol Biol 20:1655-1664

Robertson KA, Monteiro A (2005) Female Bicyclus anynana butterflies choose males on the basis of their dorsal UV-reflective eyespot pupils. Proc R Soc Lond B 272: 1541-1546

Robinson SJ, Zwaan B, Partridge L (2000) Starvation resistance and adult body composition in a latitudinal cline of Drosophila melanogaster. Evolution 54:1819-1824

Roff DA (1997) Evolutionary quantitative genetics. Chapman and Hall, New York

Roff DA, Mousseau TA (1987) Quantitative genetics and fitness: lessons from Drosophila. Heredity 58:103-118

Root TL, Price JT, Hall KR, Schneider SH, Rosenzweig C, Pounds JA (2003) Fingerprints of global warming on wild animals and plants. Nature 421:57-60

Roskam JC, Brakefield PM (1999) Seasonal polyphenism in Bicyclus (Lepidoptera: Satyridae) butterflies: different climates need different cues. Biol J Linn Soc 66:345-356

Schlichting CD, Pigliucci M (1998) Phenotypic evolution: a reaction norm perspective. Sinauer Associates, Sunderland, MA

Submitted: April 6, 2010; Accepted: May 18, 2010
Schmidt PS, Matzkin L, Ippolito M, Eanes WF (2005) Geographic variation in diapause incidence, life-history traits, and climatic adaptation in Drosophila melanogaster. Evolution 59:1721-1732

Shapiro AM (1976) Seasonal polyphenism. Evol Biol 9:259-333

Sibly RM, Atkinson D (1994) How rearing temperature affects optimal adult size in ectotherms. Funct Ecol 8:486-493

Sørensen JG, Norry FM, Scannapieco AC, Loeschcke V (2005) Altitudinal variation for stress resistance traits and thermal adaptation in adult Drosophila buzzatii from the New World. J Evol Biol 18:829-837

Stearns SC (1976) Life-history tactics: review of ideas. Q Rev Biol 51:3-47

Tauber MJ, Tauber CA, Masaki S (1986) Seasonal adaptations of insects. Oxford University Press, Oxford

Terblanche JS, Chown SL (2006) The relative contributions of developmental plasticity and adult acclimation to physiological variation in the tsetse fly, Glossina pallidipes (Diptera, Glossinidae). J Exp Biol 209:1064-1073

Trotta V, Pertoldi C, Rudoy A, Manenti T, Cavicchi S, Guerra D (2010) Thermal plasticity of wing size and shape in Drosophila melanogaster, D. simulans and their hybrids. Clim Res 43:71-79

Van Doorslaer W, Stoks R, Swillen I, Feuchtmayr H, Atkinson D, Moss B, De Meester L (2010) Experimental thermal microevolution in community-embedded Daphnia populations. Clim Res 43:81-89

van 't Hof AE, Zwaan BJ, Saccheri IJ, Daly D, Bot ANM, Brakefield PM (2005) Characterization of 28 microsatellite loci for the butterfly Bicyclus anynana. Mol Ecol Notes 5:169-172

> van 't Land J, Van Putten P, Zwaan B, Kamping A, Van Delden W (1999) Latitudinal variation in wild populations of Drosophila melanogaster: heritabilities and reaction norms. J Evol Biol 12:222-232

Via SM, Lande R (1985) Genotype-environment interaction and the evolution of phenotypic plasticity. Evolution 39: 505-522

West-Eberhard MJ (2003) Developmental plasticity and evolution. Oxford University Press, New York

Wijngaarden PJ, Brakefield PM (2001) Lack of response to artificial selection on the slope of reaction norms for seasonal polyphenism in the butterfly Bicyclus anynana. Heredity 87:410-420

> Wilson RS, Franklin CE (2002) Testing the beneficial acclimation hypothesis. Trends Ecol Evol 17:66-70

Proofs received from author(s): July 5, 2010 